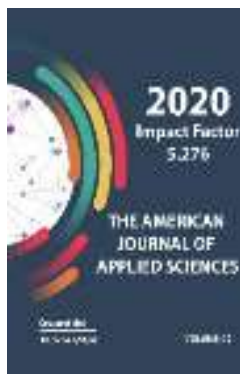

\title{
Techniques Of Cognitive Development And Competence
}

\author{
Djalolova Dilafruz Fattoxovna \\ Dotsent, Bukhara Engineering-Technological Institute, Bukhara, Uzbekistan \\ Azimova Madina Narzullayevna \\ Assistant, Bukhara Engineering-Technological Institute, Bukhara, Uzbekistan
}

Journal Website:

http://usajournalshub.c

om/index,php/tajas

Copyright: Original content from this work may be used under the terms of the creative

commons attributes

4.0 licence.

\section{ABSTRACT}

The article describes the techniques of cognitive development and competence. The students with weak accomplishments are at the lowest level of these relationships, the level characterized by a lack of relation to knowledge. The cognitive technique can be labeled in different ways, but the most important thing is to define its goal, so that it is clear to the participants, so that it brings advice /instructions/ for implementation, so that it is open to modification and transformation. It must direct the study process towards thinking, towards the stages of comprehension, towards the conditionality of the relation "memorization-competence."

\section{KEYWORDS}

Range, cognitive, intellectual, effect, assimilation, modification, transformation.

\section{INTRODUCTION}

It is a known epigram of Michel de Montaigne that it is important to understand "not who knows more, but who knows better." At a glance, this is not only so, but it is enough in order to assess the importance of knowledge. To the question "who knows more,"most teachers and students answer "the people with good memories" and by that they mean "the smart people," who absorb large volumes of information. Studies show a clear tendency to remember information as a guarantee of a better grade. Students are so busy trying to remember that they do not notice the range of cognitive abilities for rational individual work that they have developed - abilities to analyze, to interpret, to discover the resonance of knowledge, to assess problems and so forth. The various techniques directed at memorizing 
are perceived /and considered/ as "medications," which will develop only their memory, as if the memorization of information were the goal and the function of education. Unfortunately, the behavior of the teacher in this process is passive and often one of approval. And the deviant students study primarily to succeed or to make a good impression on important adults. This is their primary motivation. But to succeed, for them it means to receive the desired grade, to complete a level of a course and to graduate, and sometimes, simply to leave school without problems. Few students perceive learning as the mastering of skills for success farther into the future. This realization has always been the real beginning of the readiness for creativity and scientific discovery, of the challenge to feel confident in an unfamiliar situation. The Zlatkaability to reproduce information thus is not only not the most important, it is not an intellectual competence either - it is actually a lack of competence. What are the causes of the failures in cognitive development according to deviant students and teachers? According to the students: The large volume of information makes it difficult to understand its significance; not all that is being studied is of use; the sciences are not rendered well into the textbooks. The rhythm of teaching makes accurate comprehension difficult; the methods of evaluation make it mandatory to learn and reproduce everything word for word.

\section{MATERIALS AND METHODS}

According to the teachers: The curricula are not optimized and are overloaded; There isn't enough time to do everything; It is not feasible to work individually with deviant children; Student grades are inflated and do not reflect the achieved quality; The students nowadays do not wish to study; It is difficult to teach students with a low overall level of attainments, literacy and discipline. It can be generalized that there are three basic reasons not to work on the cognitive development of those lagging behind: The teacher solely selects the rhythm and method of teaching; the students ignore the learning process and do not comprehend it; both teachers and students lack the ability to use their time efficiently in the study process. The comprehension of the cognitive development follows the path: "I know - I say/repeat/," to "I know - I am able to /can/." Such learning has the status of an autonomous activity, which every student constructs personally and consumes individually /egoistically/. It presupposes consolidation of knowledge in the name of a new assimilation. Assimilation through thinking and through selection of a personal technology, which is part of the achievement. For children with deviant behavior this is neither a priority, nor a goal. The lack of comprehension causes both misunderstanding and conflicts [1]. The cognitive technique of learning contains a system of operations, which drill and provoke the student on the road to knowledge. "They provide the opportunity for effectiveness of the learning process, and they themselves are the subject and the result of study" [2]. The technique moves along a welldefined course /distance/, which must be traversed with specific requirements and rules. The distance is the line, which is visible, which can be traced, schematized and because of that it can be described, followed, measured in time and space. It possesses a particular structure, which makes it knowable and capable of being projected. Its internal dispositions allow for a choice of tactics, for identification of the information, for assessment and arrangement [2]. The cognitive technique offers different paths on the road to knowledge, but there are three basic elements, which are composed in the same way: Point of departure-CoursePoint of arrival Along this distance, through the elements and in them, learning takes place. Here it takes place effectively, or less effectively, depending on the motivation, the abilities and the perseverance of the student. Every distance is traversed in a precisely 
determined time, with a different informational load, by specific subjects, most often originally and uniquely, and in the case of deviants, with resistance - open or concealed. It is precisely in the distance that the specific character of the cognitive technique lies. Everyone traverses it as the El Camino Real knowing where he starts, where he would go, if he passes through all the stages and difficulties, as he feels the change within himself. For a large group of children, the point of arrival remain distant and out of reach. The technique can be guided and planned in advance. It is necessary to follow the instruction, to go through every level. If you turn to the left, in order to turn, you must turn to the right as well. The road does not lead to the starting point, you must remember the road back on your own. Analyzing it, it is possible that you might make an unexpected decision. The confidence about the course gives hope, willingness to traverse it. The discussion, the comprehension of the traversed road is an essential element of the cognitive development of all students. Confidence is being inspired through movement alongside the road of knowledge, and also hope to be able to use the new skills in real life situations. Going through the course, the problem student considers the possible options for a decision, and in so doing, begins to learn by thinking. The guidance during the assimilation of a cognitive technique consists of defining and comprehending its course of unfolding. The teacher knows that the assimilation begins with already existing stereotypes. It is necessary that the student comprehend the importance of the new situation. Otherwise he would not be motivated for work, or he would give up midway through the course. That is why it is necessary to anticipate and eliminate all unfavorable, from a pedagogical stand point, conditions in the learning process. The starting point should be the reconsideration of learning as a goal, as meaning, as responsibility. Practicing cognitive technique becomes a good announcement of the intention of mastering it. This practice is formulated didactically differently and organized methodically differently. It begins with the instructions, the advice, the form in which it would take place. Exactly what is to be done is determined and the expected outcome is defined. A contemplation of the study material is provoked, which serves as a catalyst for a specific reflection - reasoning. The familiar classical exercise is an artificially created situation, bound by rules and repetitions. It is rather "disciplined," and because of that, predicable, inspired, and for the lagging behind even tedious, tiresome and boring, because of lack of competence and motivation. In the social environment, the situations are not an aspect of an exercise. What is necessary is an instantaneous reaction and making a decision, and this is a function of learning. The cognitive style presupposes three-dimensional assimilation: cognitive-practical; cognitivesocial; cognitive-affective.

\section{RESULT AND DISCUSSION}

The level of assimilation is determined by the individual accomplishments. This applies to the modes of functioning, to the originality of unfolding and to the level of risk involved in going through the course. There are two popular polar styles. In the first style, the student /client/ assimilates the entire information - precisely and accurately. The second style is characterized by selection of the most important information, with selective and approximate, but accurate assimilation. In the first style, the student is "more autonomous," he works without additional materials and counts on repetition and his memory. In the second approach, techniques of "dependence" are used because the student definitely has requirements regarding the teaching, the information quality, his motivation, the projection of the assimilated knowledge into the future. He experiences conflicts painfully and compromises even more 
painfully, which make him choose between "the mandatory" and the unusual, which corresponds to his personal needs and interests. This social position challenges the subject to develop personal cognitive registers, to form different levels of global perception and to isolate the different, the superfluous /in his opinion/ elements of the ensemble. He acquires an intellectual level for activating the cognitive needs, which is analytical and selective in character. Thus, painfully, but successfully, are overcome the more difficult resistance sources of the perceived configuration. Students with poor achievements can assimilate neither one of these approaches. Most often they wander about between content and technique and do not achieve a good result. This confuses them and makes them nervous, and they start looking for others to blame, they grumble, deny, make up justifications. They become angry with everyone and everything. In the pedagogical literature there are numerous popular cognitive techniques, which, unfortunately, are not as popular in the pedagogical practice. Here are some of them: Techniques for learning by dominating the situations: technique with a situation; technique of inventing a situation; technique of the small situation; role playing technique; technique of learning through situational games; technique of the short film screenplays. Techniques of learning by dominating the semantics: discovering the meaning of words technique; sketching up conceptual frameworks technique; discovering the meaning of personal names technique; technique of the ideograms /symbols/; technique for seeking metaphors; technique for modeling; language copying technique; Techniques for learning by dominating the format: technique for exploring plans; technique for theorizing the practice; synthesizing technique; Delfi technique; didactic induction technique. Techniques for learning by dominating the discrimination: risk technique; selection of statements technique; discovering of the positive indicators technique; discrimination of the system technique; technique of the yellow and green card; puzzles technique. Discrimination of the communication techniques: the rotating communication technique; the opposite opinions technique; the consultation technique; the panel discussion technique; the triad technique; the argumentation technique; group observation of the alternative technique; neighbor communication technique; the interruption of the discussion technique. Techniques of dominating the projects: screenplay technique; prospects technique; stimulating the metaphors technique; exhibition technique; collage technique; brainstorm technique; Techniques of learning by discriminating the personalization: individual problem technique; "on trial" technique; "group of experts" technique; modification of the transpositions technique [3].

\section{CONCLUSION}

Cognitive learning changes the logic of classical education. It turns to wards changing the student - his motivation, his level of participation, his competence. Learning is understood as a responsibility, as a challenge and as a personal accomplishment. The cognitive repertory of the students is an indication for a specific stage of their knowledge. Through the cognitive skills an adequate amount of theoretical knowledge is being added to the overall intelligence and competence. All other techniques, operations, technologies and so on are mediated and supported. The children with poor accomplishments and the children with deviant behavior at school are in urgent need of special care and help. It is easier, of course, to classify them as hopeless and incapable of being taught. This approach would deprive us of the opportunity to discover among them unusual and talented children, who wander about in a complex labyrinth of knowledge, but who 
possess unique skills for social adaptability, which is lacking in many "straight-A students". We use the following key words : cognitive development, deviant children; Point of departure-Course- Point of arrival; cognitive technique, teachers; "I know - I say /repeat/," to "I know - I am able to /can/; competence

\section{REFERENCES}

1. Kasandrova Z. Techniques for cognitive development and competence. / collection /, 2003.

2. Pedagogy, under the editorship of Radev, Kasandrov, Z. Klasni inappropriate form for training, Hermes, 2007.

3. Radev P. Essence and techniques for the student and teacher. 1997.

4. Rick Rogers, Teaching information Skills, British Library Research, London, 1994. 